\title{
Whole and part comparisons of words and nonwords
}

\author{
HARVEY H. C. MARMUREK \\ University of Guelph, Guelph, Ontario, Canada
}

\begin{abstract}
Under conditions of sequential presentation, two words are matched more quickly than are a single letter and the first letter of a word. An exception to this whole-word advantage was reported in 1980 by Umansky and Chambers, who used word pairs as stimuli, and asked subjects to compare the entire words or the words' first letters. Experiment 1 showed that the stimulus lists used by Umansky and Chambers may not have constrained subjects to process the displays differently for wholistic and component comparisons. In those studies, the two words were identical on same trials for both wholistic and first-letter comparisons, so that first-letter decisions could have been based on wholistic information. In the present study, lists were constructed so that first-letter decisions could not be determined correctly by wholistic information (e.g., BLAME/BEACH), and the whole-word advantage was replicated. Experiment 2 tested whether wholistic comparisons are generally superior to component comparisons. For consonant strings, first-letter comparisons were made more quickly than were whole-string comparisons. These results are interpreted as support for hierarchical models of visual word processing.
\end{abstract}

A fundamental problem addressed in studies of word perception concerns the basic perceptual unit (Bradshaw, 1975). A variety of tasks have been used to measure the latency and accuracy of decisions about the identity of various basic units (e.g., single letters, letter clusters, entire words). Although a review of the outcomes obtained across methodologies is beyond the scope of the present paper, it may be concluded that the size of the functional unit in word perception varies with task demands (Bradshaw, 1975; Healy, 1976). For example, Healy (1980) showed that individual letter units are more likely to be functional in a proofreading task than in a letter detection task. Because the functional unit of processing is affected by task parameters, the functional dominance of a given unit within a task does not necessarily imply a temporal priority or dominance (Ward, 1983).

The general aim of the present studies was to examine the processing dominance (Ward, 1983) of linguistic units in the same-different comparison task, one of the paradigms used to investigate the perceptual units of word processing (Santa, Santa, \& Smith, 1977; Taylor, Miller, \& Juola, 1977). In one variant of the same-different task, decisions about the identity of two successively presented words are made more quickly than are decisions about the identity of a single letter contained in a word following presentation of a letter (Johnson, 1975). Marmurek

This research was supported by Natural Sciences and Engineering Research Council of Canada Grant No. A0684. The author thanks Mark Kozlich and Coralie Sopher for their assistance in data collection, and R. W. Proctor and two anonymous reviewers for their comments on an earlier version of this paper. Requests for reprints should be sent to Harvey H. C. Marmurek, Department of Psychology, University of Guelph, Guelph, Ont., Canada N1G 2W1.
(1977) showed that this whole-word advantage apparently depends on the prior activation of word units, because it is not obtained with simultaneous presentation. Marmurek (1977) concluded that simultaneous presentation of a letter-target and a word-comparison display allows for analytical comparisons of individual letters prior to the activation of the word unit. With successive presentations, the first item would be unitized and stored in working memory. Word units, then, would dominate processing once they had been activated in memory.

If the first and second of two successive displays were words, the comparison of the items would await unitization of the second word and the two word units would be compared. If a letter target were presented prior to a word, then the word display would not be encoded as a unit for comparison, an assumption supported by the finding that letters are searched no more quickly at the beginning of a word than at the beginning of a nonword (Krueger \& Shapiro, 1980, Experiment 1; Sloboda, 1976). Additional processing of the letters in the word would be required in order to isolate its first letter, an assumption consistent with the finding that decisions about the first letter in a word are slower than decisions about a single isolated letter (Krueger \& Shapiro, 1980, Experiment 1; Marmurek, 1977).

The empirical generalizability of the whole-word advantage under conditions of successive presentation has been challenged by Umansky and Chambers (1980). They pointed out that the studies prior to theirs included a linguistic mismatch between the forms of the target and comparison displays on trials involving letter targets (e.g., T/TABLE), and that such a mismatch did not occur on word-target trials (e.g., TABLE/TABLE). It should be noted, however, that any interference due to the linguistic mismatch cannot provide a complete account of per- 
formance in these tasks, because the mismatch also occurred with simultaneous presentation, where decisions about a letter within a word were made more quickly than were decisions about whole words. In order to control for possible negative effects of a mismatch between the linguistic level of the target and comparison displays, Umansky and Chambers (1980) presented words as both the target and the display items. In letter-comparison conditions, subjects decided whether the first letters of the words were identical, and in word-target conditions, the subjects compared entire words.

Umansky and Chambers (1980, Experiment 2) replicated the finding of Marmurek (1977) that on same trials with simultaneous presentation, first-letter decisions were made more quickly than were word decisions. In successive presentation conditions, however, there was no significant difference between first-letter and word-target same decision times. Umansky and Chambers (1980) interpreted their results to be consistent with a model of word identification, in which identification and comparison processes occur simultaneously at different levels of analysis, with the "critical assumption that letters are identified faster than letter clusters, which in turn are identified faster than words"' (p. 434).

Umansky and Chambers's model predicts that letter decisions should be faster than word decisions, yet no difference was found with successive presentation. To explain this inconsistency, Umansky and Chambers (1980, p. 441) claimed that "recency priming" facilitated the word decisions. The notion of recency priming is compatible with the idea that a word unit had been activated in memory, a condition which Marmurek (1977) and Johnson (1981) argued should lead to a whole-word advantage as found in the studies prior to Umansky and Chambers's study. An examination of the stimuli used by Umansky and Chambers suggests a possible reason for their failure to find the whole-word advantage with sequential presentation.

Umansky and Chambers (1980) manipulated the similarity of items on different trials by using words that differed in only one letter (e.g., BLAME/FLAME) or in all letters (e.g., BOUND/FRAME). Marmurek (1977) and Sloboda (1976) also manipulated similarity on different trials and found that latencies increased with increased similarity, but that a whole-word advantage was obtained at all levels of similarity. In the previous studies, the different letters in the two words varied across all positions; however, in the Umansky and Chambers study, the first letters were different, regardless of the identity of the remaining letters. As may be seen in the $\mathrm{B} / \mathrm{F}$ contrast in the examples given above, the first letters differed in both similar and dissimilar pairs; that is, information carried by the first letters of the words was sufficient for a decision about whole-word comparisons. Moreover, any difference detected between the two words implied that the first letters were different.

Therefore, subjects in both the letter-target and wordtarget conditions could base their responses on a comparison of either the whole words or the initial letters. If the comparison yielded no difference, subjects responded that the pairs shared first letters or were identical in their entirety, as directed by the task instructions. Some support for the proposal that the units of comparison were the same for letter-target and word-target trials in the successive presentation conditions studied by Umansky and Chambers (1980) is gained from a comparison of the similarity effects. For word targets, similar items took $21.5 \mathrm{msec}$ longer to compare than dissimilar items; for first-letter targets, the similarity effect was $25.5 \mathrm{msec}$. These results show that the similarity effect was comparable for letterand word-target conditions, a finding that suggests that subjects in those conditions did not process the displays as differently as the task descriptions might imply.

Experiment 1 was designed to determine whether the whole-word advantage would be found when subjects could not base their decisions for letter targets on word units alone. To preclude that strategy, Experiment 1 included a test of similarity effects on letter-target trials in which the first letters of the words were the same. Similarity was manipulated on same trials in the present study so that first-letter decisions could not be based on wholeword comparisons. For example, pairs such as BLAME/BOARD were included on same trials for firstletter targets to force subjects to respond solely on the basis of a first-letter comparison. The wholistic comparison yields an incorrect response only when the first letters of the words are identical.

To assess whether subjects were more attentive to the first letters in the first-letter target condition than in the whole-word target condition, the position of the differing letters on different trials was manipulated. For wordtarget different trials, the words differed in only one position, either the first, third, or fifth. To be correct, subjects could not base their decisions on the comparison of first letters alone. On first-letter target different trials, the first letters differed, and that was either the only difference or was accompanied by a redundant difference in the third or fifth letter. On these trials, subjects could base their decisions on the comparison of first letters alone. Some support for the hypothesis that decision processes differ for letter- and word-target trials might be gained if the effect of the type of difference should vary with the type of target.

\section{EXPERIMENT 1}

\section{Method}

Subjects. Thirty-two introductory psychology students at the University of Guelph participated in partial fulfillment of course requirements. All students had learned English as their first language and had normal or corrected-to-normal vision.

Design and Procedure. Each subject was tested with two lists of 70 items, and each list was preceded by 30 practice trials. Within each list, there were 40 trials on which the correct response was "same" and 30 trials on which the correct response was "different." For one list, subjects were to decide whether two words were identical (whole-word comparison condition), and for the other list, they were to decide whether the first letters of the words were identical (first-letter condition). The 40 same trials of the first-letter con- 
dition were of two types: either the entire words were identical (firstletter-all) or only the first letters were identical (first-letter-only). On different trials in the whole-word condition, the letters in the first, third, or fifth positions differed. In the first-letter condition, the different words differed in the first position only, or in the first and third or the first and fifth positions. The order of presentation for the list conditions was counterbalanced across subjects, and the order of trials within a list was randomized anew for each subject.

The items were presented centered on an Electrohome monitor in dark uppercase letters against a white background. The letters were $4 \mathrm{~mm}$ high and about $2 \mathrm{~mm}$ wide, and a five-letter word spanned a width of approximately $15 \mathrm{~mm}$. Subjects viewed the displays from a distance of about $60 \mathrm{~cm}$.

Subjects initiated a trial by pressing either of two microswitches when cued on the monitor to proceed when ready. A row of five asterisks appeared centered on the screen for $500 \mathrm{msec}$, and then the screen was blank for $500 \mathrm{msec}$. Next, the first word appeared centered on the screen for $500 \mathrm{msec}$, followed by a blank screen for $1,500 \mathrm{msec}$. Then the second word appeared centered on the screen for 500 msec and was followed by a blank screen. The screen remained blank until the subject pressed one of two microswitches that had been assigned to the responses "same" and "different." The assignment was counterbalanced across subjects so that half responded "same" with their preferred hand (their writing hand) and half responded "same" with their nonpreferred hand. Order of item presentation and the recording of response accuracy and response latency were controlled by a GIMIX microcomputer interfaced with the monitor and microswitches

Materials. The stimuli were five-letter high-frequency words selected from lists used by Chambers and Forster (1975) and by Umansky and Chambers (1980), with the exceptions noted below. For same trials within whole-word comparison lists, the 40 same items tested by Chambers and Forster (Experiment 2) were used. As there were two types of items that were used for same trials within first-letter comparison lists, those 40 words were randomly assigned to two sets of 20 words, and one of the sets of identical word pairs was tested in the first-letter-all comparison condition for a given subject. Each set was tested equally often across subjects. The remaining 20 same trials within a first-letter comparison list constituted the first-letter-only condition in that the pairs of words had a common first letter and differed in all other positions. Those words were selected from items used by Umansky and Chambers (1980) and were not tested in any other conditions of the study.

The 30 different trials within a word-comparison list differed in one position, and each of Positions 1, 3, and 5 was tested with the 10 pairs studied by Chambers and Forster (1975, Experiment 2). For first-letter comparison trials, all word pairs differed in the first position. Within a list, 10 pairs differed only in the first letter position, and these were the 10 pairs tested in the word-comparison list which differed in the first position. Of the 20 other different pairs in the first-letter lists, 10 differed in the first and the third positions and 10 differed in the first and fifth positions. The 10 pairs in the first-letter different trials which differed in two positions, the first and either the third or fifth, were generated by the experimenter who attempted to maintain one word of the pair from the corresponding condition in the word-comparison list. This was not possible in five cases, because no other letter could be substituted in the first position and third or fifth position to form a word (e.g. STORE/STORM). All the stimuli used in the study are listed in Appendix A. The order of the two words for pairs with different members was counterbalanced across subjects.

\section{Results and Discussion}

Analyses were carried out on the mean correct latencies and mean error rates; the means were determined by using subjects as the sampling unit. Analyses of means using items as the sampling unit were generally in agree-
Table 1

Mean Correct Latencies (msec) and Mean Error Rates in Experiment 1

\begin{tabular}{|c|c|c|c|c|c|c|c|}
\hline \multirow[b]{2}{*}{ Trial } & \multirow[b]{2}{*}{ Measure } & \multirow{2}{*}{\multicolumn{3}{|c|}{ Whole Condition }} & & \multicolumn{2}{|c|}{$\begin{array}{c}\text { First-Letter } \\
\text { Condition }\end{array}$} \\
\hline & & & & & & All & Only \\
\hline \multirow{4}{*}{ Same } & Latency & \multicolumn{3}{|c|}{782} & \multicolumn{2}{|r|}{949} & 1,177 \\
\hline & \multirow[t]{3}{*}{ Error Rate } & \multicolumn{3}{|c|}{.021} & & .023 & .061 \\
\hline & & \multicolumn{3}{|c|}{ Whole Condition } & \multicolumn{3}{|c|}{ First-Letter Condition } \\
\hline & & First & Third & Fifth & First & Third & Fifth \\
\hline \multirow{2}{*}{ Different } & Latency & 1,014 & 1,173 & 1,132 & 1,071 & 1,013 & 1,053 \\
\hline & Error Rate & .018 & .035 & .041 & .019 & .022 & .025 \\
\hline
\end{tabular}

ment with the analyses reported here. The mean latencies for the item analyses are presented in Appendix A.

Same trials. The mean correct latencies are shown in Table 1. A one-way repeated measures analysis of variance showed that the means were significantly different $[F(2,62)=18.78, p<.001, M S e=66,916]$. Pairwise comparisons showed that first-letter decisions were significantly slower than whole-word decisions when all letters were the same $[F(1,62)=20.48, p<.001]$, and that first-letter decisions were even slower when the first letters were the only identical letters in the two words $[F(1,62)=7.98, \mathrm{p}<.01]$.

Analyses of the error rates shown in Table 1 revealed that a significantly higher rate of errors occurred in the first-letter comparison list when only the first letters were identical $[F(2,62)=17.77, p<.001, M S \mathrm{e}=42.76]$. As can be seen in Table 1, error rates tended to be positively correlated with mean correct latencies.

The correct "same" latencies showed a whole-word advantage with successive presentation of two words. The major difference between the present study and the Umansky and Chambers (1980) study, which failed to find the effect, was that the stimuli in the present study precluded subjects from comparing whole-word units in order to make a correct response in first-letter comparison lists; that is, for half the items in a list, the first letters were the only identical letters. Although subjects were precluded from comparing whole units in first-letter comparison lists, they did not restrict comparison to only the first letters. The latencies were slowed down significantly by the presence of the four different letters.

According to the multilevel view of word processing (Marmurek, 1977), subjects unitize the first word of a pair. In order to compare the first letter of that unit to the first letter of the next word, additional processing would be required to isolate and compare the first letters. Johnson and Marmurek (1978) have shown that the additional processing is not initially constrained to the relevant position. They found that when a letter target did not occur in the predesignated position, its occurrence elsewhere in a word slowed correct decision times. In the present study, differences that occurred in the irrelevant positions slowed correct "same" latencies. Together, 
these results would be compatible with the hypothesis that first-letter decisions involve some initial processing of all the letters in the two words, followed by a comparison of the letters in the first position of each word. The process of rechecking the first letters may be more deliberate when there is a great degree of noise in the system, as a consequence of the number of mismatching letters in the two words (Krueger, 1978).

Different trials. The mean correct latencies on different trials are presented in the lower half of Table 1. A 2 (comparison) $\times 3$ (difference) ANOVA showed that neither main effect was significant [for comparison, $F(1,31)=1.83, M S e=47,422 ;$ and for difference, $F(2,62)=1.06, M S e=24,791]$. The two factors, however, entered into a significant interaction $[F(2,62)=$ $12.98, p<.001, M S e=15,745]$. A comparison of the latencies to items which differed in only the first position showed that the whole-word advantage was not significant $[F(1,62)=2.4, p>.05]$. Analyses of simple effects showed that the effect of the type of difference was significant for the whole-word comparison list $[F(2,62)=$ $12.18, p<.001]$, but not for the first-letter comparison list $[F(2,62)=1.33, p>.05]$.

The analyses of error rates on different trials showed that on word-comparison trials, significantly fewer errors occurred when the different letter was in the first position $[F(2,62)=7.91, p<.001, M S e=48.1]$. On firstletter comparison trials, there was no effect of another different letter elsewhere in the two words $[F(2,62)=$ $1.08, p>.05, M S \mathrm{e}=27.2 \mathrm{]}$.

The correct latency results on different trials replicated the null effect of the type of comparison on first-letter different trials reported by Marmurek (1977) and by Umansky and Chambers (1980). However, subjects in the present study did not treat the displays in the same manner for the word-comparison and first-letter comparison conditions. On word-comparison trials, subjects were slower to detect a difference if it did not occur in the first position. They may have scanned in a left-to-right order or allocated more attention to the first position while checking all positions in parallel. For first-letter comparisons, there was no effect of a redundant difference elsewhere in the displays, a pattern suggesting that subjects restricted their rechecking to the first position.

The absence of an effect of the identity of items in noncritical positions on different first-letter comparison trials contrasts with the large interference effect found on same first-letter comparison trials. The difference might be due to the greater degree of response competition present on the same trials where four positions indicated an incorrect "different" response (Krueger \& Shapiro, 1980). Overall, the results suggest that word comparisons are initially wholistic but subject to analytical rechecking. First-letter comparisons involve an attentional shift to the critical predesignated location, but that shift is not completed prior to some processing of extraneous letter identities.

\section{EXPERIMENT 2}

One interpretation of the whole-word advantage is that word units, once having been activated in memory, conceal the identity of their component letters (Johnson, 1981). Experiment 2 was designed to test the hypothesis that nonwords, which have no unitary representation in memory, would not conceal their individual letters. Sloboda (1976) and Krueger and Shapiro (1980) showed that first-letter target decisions take no longer in a word list than in a list of nonwords. However, in those studies, a single letter preceded a multiletter display, and those conditions might not lead to unitization of the comparison display. Silverman (1976, Experiment 3) showed that discriminations based on two letters within a string are made more quickly for words than for nonwords, and O'Hara and Eriksen (1979) found that a word produces less interference than a nonword when placed between two comparison letters. These results support the hypothesis that letters are more likely to be integrated when embedded in words than in nonwords.

A recent set of studies by Prinzmetal and Millis-Wright (1984) suggest that some features of a multiletter display are more likely to be concealed when the display forms a pronounceable or familiar unit. In those studies, subjects had to report the color in which a target letter was presented. The probability of confusing the target's color with the color of another letter in the display was greater when the target occurred in a word than when it was embedded in a letter string. Those results indicate that lower level information is less salient in a word display than in a nonword display.

If letter strings are not integrated as wholistic units, a letter within a string should be identified more quickly than the entire string. That is, attention could be directed at the letter-level detectors without interference from higher order levels. Pronounceable strings and consonant strings were contrasted in Experiment 2 in order to assess the role of pronounceability in unitization (Prinzmetal \& Millis-Wright, 1984, Experiment 3).

\section{Method}

Subjects. The subjects were 64 undergraduate psychology students who participated in partial fulfillment of course requirements. All subjects had learned English as their first language and had normal or corrected-to-normal vision. No subject had participated in Experiment 1.

Design and Procedure. Subjects were assigned to one of two groups in a block randomized fashion. One group was tested with orthographically regular nonwords (pseudowords) and the other with consonant strings. Each subject was tested with two lists, one involving whole-string comparisons and the other first-letter comparisons. The order of lists was counterbalanced across subjects for each group. The procedural details were identical to those used in Experiment 1.

Materials. The stimuli were generated by transforming the materials used in Experiment 1. For pseudowords, vowel substitutions were made so the new strings were regular in pronuncia- 
tion. Consonant strings were formed by substituting for each vowel in the base word a consonant that was visually similar to the vowel (Townsend, 1971). The pseudoword and consonant strings are listed in Appendix B.

\section{Results and Discussion}

Same trials. The mean correct latencies are shown in Table 2. A 2 (string) $\times 3$ (comparison) mixed ANOVA showed a significant effect of comparison $[F(2,124)=$ $8.26, \mathrm{p}<.001, M S \mathrm{Se}=32,686]$ and a significant interaction effect $[F(2,124)=20.12, p<.001]$. Analyses of the comparison effect for each type of string showed that first-letter-only comparisons yielded the longest latencies for pseudowords $[F(2,124)=9.33]$. For consonant strings, whole-string comparisons were slowest $[F(2,124)=23.84]$. Pairwise comparisons of the two types of strings at each level of comparison showed an advantage for pseudowords in whole-string comparisons $[F(1,124)=10.59]$, and a letter-string advantage in firstletter-only comparisons $[F(1,124)=6.49]$.

The error rates, shown in Table 2, tended to be highest in those conditions yielding the longest latencies. The comparison effect was significant $[F(2,124)=4.18$, $M S e=53.87]$, but the interaction with string was also statistically significant $[F(2,124)=8.45, p<.001]$. For pseudowords, the error rates were highest when only the first letters were the same $[F(2,124)=6.13]$, and for consonant strings the error rates were highest for comparisons of all letters $[F(2,124)=6.41]$.

The preceding analyses showed that a letter at a predesignated position within a consonant string is processed more quickly than are all the letters in the string. Furthermore, that decision is not affected by the identity of the letters in the noncritical positions. These results support the hypothesis that on first-letter comparison trials involving letter-string displays there was no activation of a unit representing the entire string to control the comparison of first letters. For pseudowords, however, there was some evidence of a wholistic comparison in that decisions about first letters were slowed by the presence of different letters in the noncritical position. Interference from extraneous letters has been found in same-different and letter identification tasks where neither words nor pseudowords are formed by the letter displays (Eriksen, O'Hara, \& Eriksen, 1982; Santee \& Egeth, 1982). In those studies, however, interference might have arisen from items that had been associated with competing responses across trials. It may be that these overlearned items are processed automatically (Shiffrin \& Schneider, 1977), whereas the changing consonant strings used in the present study were subjected to more controlled processing.

In contrast to the findings of Experiment 1, in which word displays were used, pseudowords did not show an advantage for whole-string decisions over first-letter decisions when the two pseudowords were identical. If units representing pseudowords are activated in working memory prior to the onset of the comparison display, then pseudowords might be expected to be processed in a manner similar to words. For whole-string comparisons, a unitization of the second pseudoword would be followed by a comparison with the unit in working memory. On first-letter trials, there would be some analysis of all letters, but the response would be withheld until a check of the critical position.

A comparison of the mean "same" latencies for items across the two experiments showed that whole-display decisions were significantly faster for words than for pseudowords $[F(1,78)=38.47, p<.001, M S e=11,073]$, and that there was no significant difference between the latencies for the two types of items on first-letter-all trials $[F(1,78)=1.05, M S \mathrm{e}=13,484]$. These results suggest

Table 2

Mean Correct Latencies (msec) and Error Rates in Experiment 2

\begin{tabular}{|c|c|c|c|c|c|c|c|c|}
\hline \multirow[b]{2}{*}{ Trial } & \multirow[b]{2}{*}{ Display } & \multirow[b]{2}{*}{ Measure } & \multirow{2}{*}{\multicolumn{3}{|c|}{ Whole Condition }} & \multicolumn{3}{|c|}{ First-Letter Condition } \\
\hline & & & & & & All & & $\overline{\text { Only }}$ \\
\hline \multirow{5}{*}{ Same } & \multirow{2}{*}{ Pseudowords } & Latency & \multicolumn{3}{|c|}{893} & 909 & & 1044 \\
\hline & & Error Rate & \multicolumn{3}{|c|}{.031} & .035 & & .058 \\
\hline & \multirow{3}{*}{$\begin{array}{l}\text { Consonant } \\
\text { Strings }\end{array}$} & & \multirow{2}{*}{\multicolumn{3}{|c|}{1139}} & & & \\
\hline & & Latency & & & & 823 & & 839 \\
\hline & & Error Rate & \multicolumn{3}{|c|}{.067} & .027 & & .031 \\
\hline & & & \multicolumn{3}{|c|}{ Whole Condition } & \multicolumn{3}{|c|}{ First-Letter Condition } \\
\hline \multirow{7}{*}{ Differen } & \multirow{4}{*}{ Pseudowords } & & First & Third & Fifth & First & Third & Fifth \\
\hline & & Latency & 1056 & 1209 & 1124 & 1007 & 985 & 1005 \\
\hline & & Error Rate & .025 & .058 & .067 & .033 & .013 & .006 \\
\hline & & & & & & & & \\
\hline & \multirow{3}{*}{$\begin{array}{l}\text { Consonant } \\
\text { Strings }\end{array}$} & Latency & 1116 & 1488 & 1322 & 967 & 941 & 894 \\
\hline & & & & & & & & \\
\hline & & Error Rate & .033 & .078 & .065 & .041 & .025 & .025 \\
\hline
\end{tabular}


that pseudowords fail to yield a whole-display comparison advantage because it takes longer either to unitize the pseudoword display or to compare two pseudoword units. The absence of a difference between words and pseudowords in latencies for first-letter-all decisions implies no difference in attending to a predesignated position. That the processes involved in first-letter comparisons are similar for word and pseudoword units is indexed further by the lack of a significant difference in the item analysis that compared word and pseudoword first-letter-only latencies $[F(1,38)=0.27, M S e=40,718]$.

Different trials. The mean correct latencies for different trials are presented in the lower half of Table 2. A 2 (comparison) $\times 2$ (string) $\times 3$ (difference) ANOVA showed that two second-order interactions were significant. The comparison $\times$ string interaction $[F(1,62)=$ $10.82, M S e=78,256]$ showed that comparisons of entire displays were significantly slower for letter strings than for pseudowords $[F(1,62)=4.19]$, whereas there was no difference between the two types of displays in decisions about first letters $[F(1,62)=0.34]$. The comparison $\times$ difference interaction $[F(2,124)=13.85$, $M S e=49,302]$ showed that differences in letters not in the first position influenced whole-display decisions $[F(2,124)=12.11]$, but not first-letter decisions $[F(2,124)$ $=1.96]$. The three-way interaction was not significant $[F(2,124)=1.61]$. That is, both pseudoword and consonant-string decisions were slower when the sole difference for entire display comparisons occurred in a noninitial position, and this result is consistent with the hypothesis that the rechecking process preceding a "different" response is biased toward the first letter for both types of displays.

These results support the view that decisions about consonant strings are controlled by analyses of individual letters. In a whole-display condition, more comparisons will be carried out among the individual letter units of consonant strings than between the multiletter units of wordlike strings. When the identity of a single letter in a predesignated position is the basis of a decision, then a single comparison is required for letter strings, although the process of shifting attention to the critical location takes up time prior to the decision.

Analyses of the mean error rates shown in Table 2 showed that the error rates were significantly greater for consonant strings than for pseudowords $[F(1,62)=4.34$, $p<.05, M S e=133.23]$. The comparison $\times$ difference interaction was significant $[F(2,124)=19,39, p<.001$, $M S e=120.32]$. For wholistic comparisons, differences occurring in the third and fifth position were missed more often than was a difference in the first position $[F(2,124)=13.32]$. The type of difference had no significant effect on errors for first-letter decisions $[F(2,124)=1.36]$. The pattern of error rates is consistent with the hypothesis that multiletter units only facilitate wholistic comparisons.

\section{GENERAL DISCUSSION}

The present studies have shown that whole displays are compared more quickly than are parts of the displays when the displays form words and are presented successively. The failure of Umansky and Chambers (1980) to find this effect may be attributed to their use of the same displays on whole and part comparison trials, a method which does not ensure that whole and part comparisons are sufficiently distinct. The sensitivity of the whole-word advantage to the stimulus ensemble may be viewed, then, as another instance of how task parameters influence the processing dominance of various aspects of visual forms (Crist, 1981; Ward, 1983).

Umansky and Chambers (1980) discussed the implications of the whole-word advantage for hierarchical and race models of word identification. Both classes of models assume that a word may be represented at various levels ranging from low-level features, to letters, to multiletter units such as words. Hierarchical models (Estes, 1975; McClelland \& Rumelhart, 1981; Paap, Newsome, McDonald, \& Schvaneveldt, 1982) assume that low-level detectors provide input to the higher level detectors. The preliminary stages of activation are unconscious, and once the highest level detector is activated, it will control subsequent processing. For example, the interactive activation model proposed by McClelland and Rumelhart (1981) assumes that lexical units provide excitatory feedback to their constituent letters, whereas the activation-verification model proposed by Paap et al. (1982) assumes that lexical units, rather than letter units, control verification and decision processes about constituent letters. Neither of these models was developed to explain the whole-word advantage, but both are compatible with it. That is, both models imply that same-different comparisons for activated high-level units could be made directly, whereas letter-level comparisons would await further processing of the component detectors.

The major distinction between the race model (Umansky \& Chambers, 1980) and hierarchical models is the assumption in the former that letter identification is made more quickly than is word identification. If only the first letters of two words are to be compared, then that comparison should be made more quickly than the comparison of two entire words. Hierarchical models assume that under conditions in which a word unit has been activated, additional time would be required to change the locus of processing to the lower level letter representations. The absence of a whole-word advantage on "different" trials may be attributed to a rechecking process (Krueger, 1978), which involves letter-level comparisons for word targets. If positional uncertainty about a single letter difference is added to the word-target condition, then first-letter decisions will be faster.

Hierarchical accounts of the whole-word advantage suggest that decisions about components should not be 
delayed when a higher order unit is unavailable for activation. The results of Experiment 2 supported this hypothesis, as the first letters in consonant strings were compared more quickly than were entire strings. The firstletter decisions on same trials had similar latencies for consonant strings sharing all letters and those sharing only first letters. For words and pseudowords, first-letter latencies were significantly longer on same trials where only the first letters were identical. Those results would be expected if units representing all the letters had been activated for words and pseudowords on first-letter trials, whereas only first-letter units had been activated for consonant strings.

Why would higher order units be activated when subjects know in advance that decisions are to be based on first letters? It may be that the activation automatically proceeds to the highest level. The utility of that process is consonant with the proposal that phonological and lexical codes provide a robust description of a visual stimulus (Henderson, 1982): These codes may limit memory demands and facilitate "conscious scrutiny of lower-level representations of the stimulus" (p. 282). Johnston (1981) offered a similar explanation for the higher probability of correctly identifying a letter when the letter is presented in a word rather than alone or in a nonword. However, in some cases those codes may reduce efficient processing of lower level information (Prinzmetal \& MillisWright, 1984), as shown in the present studies by the deleterious effects of irrelevant letter identity for words but not for consonant strings. Furthermore, the beneficial effects of the higher order code depend on how attentional resources are deployed (Johnston \& McClelland, 1974).

There is some evidence that attending to all the letters in a word requires less attentional capacity than does attending to a single letter in a word. LaBerge (1983, Experiment 1) asked subjects to make decisions about either the category membership of a word or the identity of a letter within a word. Primary task latencies were longer for letter decisions than for category decisions, and responses to a visual probe stimulus were made more quickly when the main task involved category decisions. These results are consistent with the view that isolating a letter within a word requires more capacity than attending to the entire word. The whole-word advantage, then, may be determined by the capacity demands for distributing attention across all positions relative to those for focusing on a designated position. If that view is correct, then the pattern of demands should be reversed for consonant strings, and there is some recent evidence to that effect (Marmurek, 1984).

These attentional limitations suggest that for maximal processing efficiency, the display containing the letter target will be encoded to the highest possible level prior to the onset of the comparison display. For whole-display comparisons, higher order units will afford fewer demands on processing than will a large number of lower order units. For first-letter comparisons, the identities of the individual letters represented by a higher order unit remain active prior to the wholistic encoding of the comparison display. This must be the case, since the identity of letters in the irrelevant positions mediate performance. Consonant strings gain an advantage in first-letter comparisons, because no higher-order unit identifying all the letters is activated. Rather, a single letter unit is held in working memory, and the comparison process awaits only isolation of the leftmost letter in the comparison display.

In conclusion, it has been shown that the whole-word advantage is obtained with sequential presentation under conditions in which letter targets are specified within a word. The critical factor distinguishing the present studies and those of Umansky and Chambers (1980) is the nature of the stimulus lists. Stimuli must be selected so as to ensure that subjects process the displays differently for letter- and word-target conditions. The whole-word advantage is best accounted for by hierarchical models, which assume that activation of higher order units controls comparison processes. Where higher order units are available, attention to the whole unit may impose fewer demands on capacity than does attention to local components.

\section{REFERENCES}

Bradshaw, J. L. (1975). Three interrelated problems in reading: A review. Memory \& Cognition, 3, 123-134.

Chambers, S. M., \& Forster, K. I. (1975). Evidence for lexical access in a simultaneous matching task. Memory \& Cognition, 3, 549-559.

CRIST, W. B. (1981). Matching performance and the similarity structure of the stimulus set. Journal of Experimental Psychology: General, $110,269-296$.

Eriksen, C. W., O'Hara, W. P., \& Eriksen, B. (1982). Response competition in same-different judgments. Perception \& Psychophysics, 32, 261-270

Estes, W. K. (1975). The locus of inferential and perceptual processes in letter identification. Journal of Experimental Psychology: General, 104, 122-145

HEALY, A. F. (1976). Detection errors on the word the: Evidence for reading units larger than letters. Journal of Experimental Psychology: Human Perception \& Performance, 2, 235-242.

Healy, A. F. (1980). Proofreading errors on the word The: New evidence on reading units. Journal of Experimental Psychology: Human Perception \& Performance, 6, 45-57.

HeNDERSON, L. (1982). Orthography and word recognition in reading. London: Academic Press.

Johnson, N. F. (1975), On the function of letters in word identification: Some data and a preliminary model. Journal of Verbal Learning \& Verbal Behavior, 14, 17-29.

JoHNSON, N. F. (1981). Integration processes in word recognition. In O. J. L. Tzeng \& H. Singer (Eds.), Perception of print: Reading research in experimental psychology (pp. 29-63). Hillsdale, NJ: Erlbaum.

JoHnSON, N. F., \& MARMUREK, H. H. C. (1978). Identification of words and letters within words. American Journal of Psychology, 91 , 401-415

JOHNSTON, J. C. (1981). Understanding word perception: Clues from studying the word-superiority effect. In O. J. L. Tzeng \& H. Singer (Eds.), Perception of print: Reading research in experimental psychology (pp. 65-84). Hillsdale, NJ: Erlbaum.

Johnston, J. C., \& McClelland, J. L. (1974). Perception of letters in words: Seek not and ye shall find. Science, 184, 1192-1194.

Krueger, L. E. (1978). A theory of perceptual matching. Psychological Review. 85, 278-304. 
Krueger, L. E., \& Shapiro, R. G. (1980). Repeating the target neither speeds nor slows its detection: Evidence for independent channels in letter processing. Perception \& Psychophysics, 28, 68-76.

LABERGE, D. (1983). Spatial extent of attention to letters and words. Journal of Experimental Psychology: Human Perception \& Performance, 9, 371-379.

Marmurek, H. H. C. (1977). Processing letters in words at different levels. Memory \& Cognition, 5, 67-72.

Marmurek, H. H. C. (1984, November). Attending to levels of words and nonwords. Paper presented to the Child Research and Study Center, Albany, NY.

McClelland, J. L., \& Rumelhart, D. E. (1981). An interactive activation model of context effects in letter perception: Part 1. An account of basic findings. Psychological Review, 88, 375-407.

O'HaRA, W., \& ERIKSEN, C. W. (1979). Word unitization examined using an interference paradigm. Bulletin of the Psychonomic Society, 14, 81-84.

Paap, K. R., Newsome, S. L., McDonald, J. E., \& Schvaneveldt, R. W. (1982). An activation-verification model for letter and word recognition: The word-superiority effect. Psychological Review, 89, 573-594.

Prinzmetal, W., \& Millis-Wright, M. (1984). Cognitive and linguistic factors affect visual feature integration. Cognitive Psychology, 16, 305-340.
Santa, J. L., Santa, C. \& Smith, E. E. (1977). Units of word recognition. Evidence for the use of multiple units. Perception \& Psy chophysics, 22, 585-591.

SANTEE, J. L., \& Egeth, H. E. (1982). Do reaction time and accuracy measure the same aspects of letter recognition? Joumal of Experimental Psychology: Human Perception \& Performance, 8, 489-501.

SHIFFrin, R. M., \& SCHNEIDER, W. (1977). Controlled and automatic human information processing: II. Perceptual learning, automatic attending, and a general theory. Psychological Review, 84, 124-190.

Silverman, W. P. (1976). Can "words" be processed as integrated units? Perception \& Psychophysics, 20, 143-152.

Sloboda, J. A. (1976). Decision times for word and letter search: A wholistic word identification model examined. Journal of Verbal Learning \& Verbal Behavior, 15, 93-101.

TAYlor, G. A., Miller, T. J., \& JUOLA, J. F. (1977). Isolating visual units in the perception of words and nonwords. Perception \& Psychophysics, 21, 377-386.

TownSEND, J. T. (1971). Theoretical analysis of an alphabetic confusion matrix. Perception \& Psychophysics, 9, 40-45.

Umansky, J. A., \& Chambers, S. M. (1980). Letters and words in word identification. Memory and Cognition, 8, 433-446.

WARD, L. M. (1983). On processing dominance: Comment on Pomerantz. Journal of Experimental Psychology: General, 112, 541-546.

APPENDIX A-1

Mean Correct Latencies (in Milliseconds) for Same Items in Experiment 1

\begin{tabular}{lcclcc}
\hline & \multicolumn{2}{c}{ Type of Comparison } & & \multicolumn{2}{c}{ Type of Comparison } \\
\cline { 2 - 3 } \cline { 5 - 6 } & Whole & First-Letter-All & & Whole & First-Letter-All \\
\hline BRUSH & 793 & 908 & QUEEN & 719 & 911 \\
BUILD & 754 & 953 & SCALE & 857 & 746 \\
CATCH & 795 & 808 & SCORE & 657 & 836 \\
CLOTH & 777 & 834 & SHORT & 648 & 880 \\
DEATH & 668 & 850 & SLEEP & 792 & 937 \\
DRINK & 887 & 835 & SMOKE & 729 & 842 \\
FAITH & 749 & 766 & SOUND & 671 & 930 \\
FIGHT & 617 & 909 & SPACE & 709 & 763 \\
FOUND & 712 & 928 & SPEND & 830 & 860 \\
FRUIT & 761 & 975 & STAGE & 848 & 801 \\
GUARD & 614 & 896 & STAND & 792 & 903 \\
GUESS & 718 & 951 & STATE & 653 & 781 \\
KNIFE & 914 & 945 & THREE & 748 & 700 \\
LEARN & 749 & 871 & THREW & 728 & 938 \\
NOISE & 704 & 974 & TRAIN & 745 & 853 \\
PAINT & 768 & 1,053 & VOICE & 859 & 749 \\
PLANT & 912 & 1,035 & WHEAT & 805 & 825 \\
PORCH & 877 & 931 & WHITE & $\mathbf{8 8 8}$ & 940 \\
PRICE & 758 & 764 & WORTH & 723 & 1,028 \\
PRIDE & 887 & 1,132 & WOULD & $\mathbf{7 5 1}$ & 945 \\
\hline
\end{tabular}

APPENDIX A-2

Mean Correct Latencies (in Milliseconds) for First-Letter-Only Items

\begin{tabular}{lrlr}
\hline BENCH/BOARD & 973 & GROUP/GUARD & 1,025 \\
BIRTH/BEAST & 1,148 & MARCH/MIGHT & 1,053 \\
CHEST/CLAIM & 1,083 & NIGHT/NURSE & 1,299 \\
CHIEF/CREAM & 1,393 & PHASE/POUND & 1,138 \\
CHILD/COURT & 1,007 & SHAPE/SWEET & 1,082 \\
COAST/CRIME & 1,415 & SIGHT/STORE & 1,482 \\
DANCE/DRILL & 1,396 & TEETH/TRUCK & 988 \\
FAULT/FLOOR & 1,282 & THING/TRAIL & 1,098 \\
FLOUR/FRUIT & 1,115 & WASTE/WOUND & 1,339 \\
GRASS/GUEST & 989 & WHEEL/WORLD & 967 \\
\hline
\end{tabular}


APPENDIX A-3

Mean Correct Latencies (in Milliseconds) for Different Trials in Experiment 1

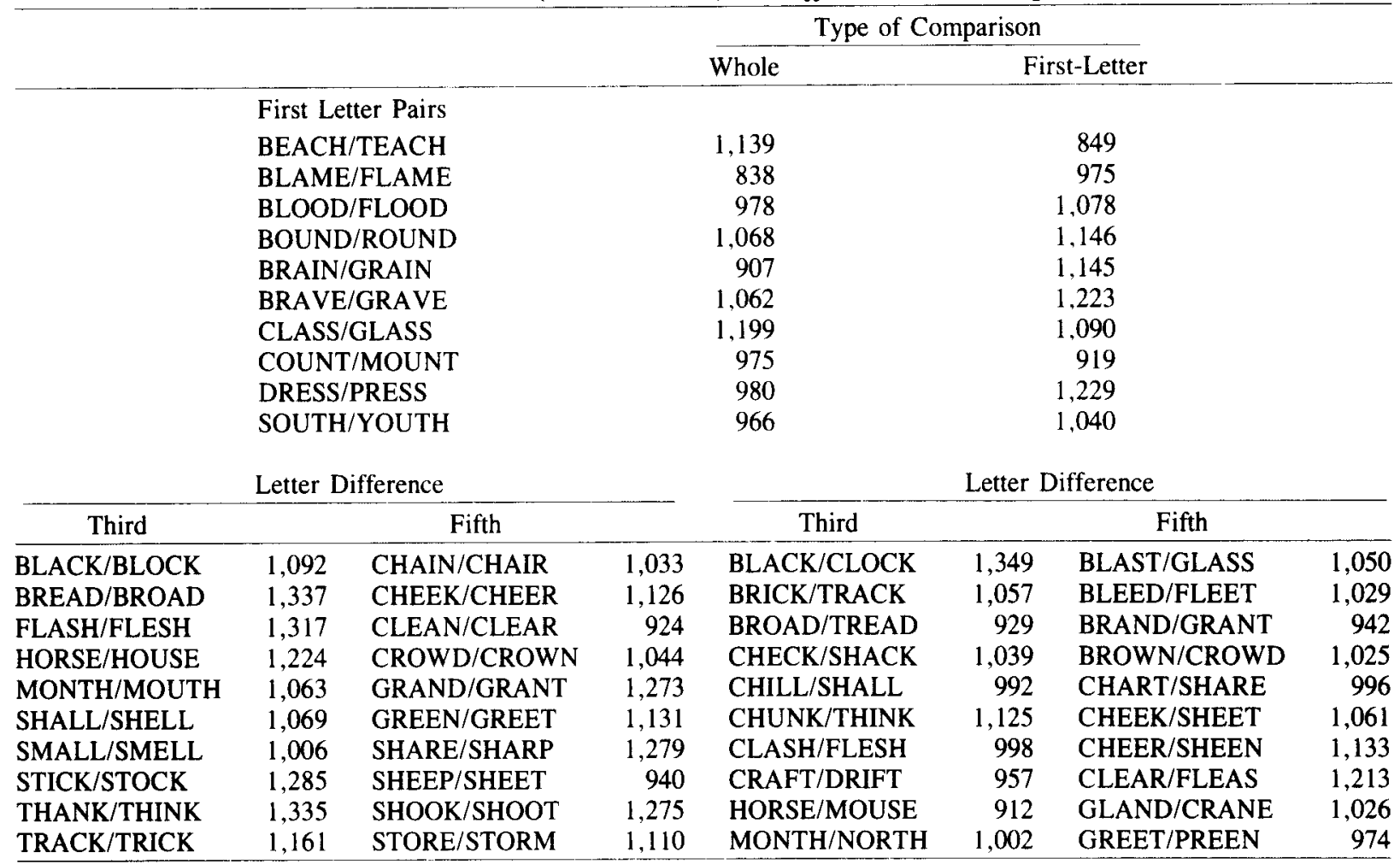

APPENDIX B-1

Mean Correct Latencies (in Milliseconds) for Same Pseudowords in Experiment 2

\begin{tabular}{lrclrr}
\hline & \multicolumn{2}{c}{ Type of Comparison } & & \multicolumn{2}{c}{ Type of Comparison } \\
\cline { 2 - 3 } \cline { 5 - 6 } & Whole & First-Letter-All & & Whole & First-Letter-All \\
\hline BRISH & 1,230 & 981 & QUOON & 973 & 1,228 \\
BAILD & 971 & 734 & SCILE & 859 & 962 \\
CETCH & 1,008 & 800 & SCIRE & 862 & 991 \\
CLUTH & 819 & 1,146 & SHURT & 783 & 966 \\
DOATH & 788 & 1,151 & SLAEP & 1,016 & 744 \\
DRENK & 846 & 761 & SMIKE & 896 & 1,152 \\
FOITH & 916 & 773 & SAUND & 822 & 733 \\
FOGHT & 1,117 & 959 & SPUCE & 774 & 722 \\
FAUND & 904 & 867 & SPIND & 1,002 & 1,153 \\
FROIT & 870 & 1,072 & STOGE & 838 & 921 \\
GUERD & 1,077 & 921 & STUND & 944 & 1,020 \\
GUOSS & 856 & 899 & STITE & 873 & 1,011 \\
KNOFE & 948 & 997 & THROO & 796 & 932 \\
LOARN & 1,168 & 749 & THRAW & 853 & 838 \\
NAISE & 870 & 929 & TROIN & 1,043 & 893 \\
PAUNT & 816 & 857 & VAICE & 933 & 936 \\
PLONT & 826 & 852 & WHOAT & 1,046 & 974 \\
PRACE & 800 & 769 & WHUTE & 1,103 & 924 \\
PURCH & 966 & 740 & WARTH & 641 & 729 \\
PRODE & 852 & 868 & WAULD & 699 & 896 \\
\hline
\end{tabular}


APPENDIX B-2

Mean Correct Latencies (in Milliseconds) for Same Consonant Strings in Experiment 2

\begin{tabular}{lrrlrr} 
& \multicolumn{2}{c}{ Type of Comparison } & & \multicolumn{2}{c}{ Type of Comparison } \\
\cline { 2 - 3 } & Whole & First-Letter-All & & Whole & First-Letter-All \\
\hline BRHSH & 1,069 & 684 & QHTTN & 931 & 733 \\
BHTLD & 1,057 & 814 & SCKLT & 1,058 & 671 \\
CKTCH & 1,255 & 688 & SCDRT & 1,164 & 996 \\
CLDTH & 995 & 859 & SHCRT & 935 & 608 \\
DLKTH & 1,048 & 812 & SLTTP & 1,044 & 863 \\
DRLNK & 1,034 & 1,018 & SMCKT & 1,079 & 859 \\
FKLTH & 1,442 & 753 & SCHND & 1,098 & 871 \\
FLGHT & 1,119 & 843 & SPKCT & 1,195 & 1,045 \\
FCHND & 1,248 & 1,009 & SPTND & 1,130 & 800 \\
FRHLT & 977 & 715 & STKGL & 1,154 & 791 \\
GHKRD & 1,195 & 1,045 & STKND & 1,290 & 892 \\
GHTSS & 867 & 771 & STKTL & 1,072 & 895 \\
KNLFT & 1,393 & 814 & THRLL & 1,099 & 1,087 \\
LTKRN & 1,148 & 778 & THRLW & 1,108 & 687 \\
NCLST & 1,330 & 937 & TRKLN & 1,090 & 881 \\
PKLNT & 1,055 & 733 & VDLCT & 1,290 & 892 \\
PLKNT & 1,172 & 712 & WHLKT & 1,518 & 656 \\
PDRCH & 1,072 & 895 & WHLTF & 1,089 & 626 \\
PRLCT & 1,162 & 764 & WCRTH & 1,158 & 936 \\
PRLDT & 1,029 & 915 & WCHLD & 1,048 & 780 \\
\hline
\end{tabular}

\section{APPENDIX B-3}

Mean Correct Latencies (in Milliseconds) for First-Letter-Only Pseudowords and Consonant Strings

\begin{tabular}{|c|c|c|c|c|c|c|c|}
\hline \multicolumn{4}{|c|}{ Pseudowords } & \multicolumn{4}{|c|}{ Consonant Strings } \\
\hline BINCH/BOURD & 1,187 & GROAP/GUERD & 1,153 & BLNCH/BCHRD & 627 & GRCKP/GHTRD & 927 \\
\hline BORTH/BEIST & 887 & MIRCH/MOGHT & 1,407 & BCRTH/BFLST & 762 & MLRCH/MCGHT & 680 \\
\hline CHAST/CLOIM & 1,725 & NOGHT/NARSE & 1,061 & CHKST/CLDTM & 1,008 & NCGHT/NKRSL & 783 \\
\hline CHAIF/CROAM & 1,161 & PHISE/POAND & 1,219 & CHKLF/CRDKM & 743 & PHLSE/PCKND & 715 \\
\hline CHOLD/COART & 1,043 & SHIPE/SWOOT & 1,725 & CHDLD/CDKRT & 963 & SCGHT/STLRF & 715 \\
\hline COUST/CROME & 1,154 & SOGHT/STIRE & 1,206 & CDHST/CRDML & 722 & SHLPF/SWCCT & 1,008 \\
\hline DONCE/DRALL & 1,194 & TEATH/TRECK & 1,161 & DCNCT/DRKLL & 783 & THLNG/TRCTL & 801 \\
\hline FOULT/FLEER & 1,039 & THENG/TROIL & 909 & FCHLT/FLTTR & 801 & TLKTH/TRLCK & 743 \\
\hline FLOAR/FRAIT & 981 & WOSTE/WAUND & 889 & FLCKR/FRKLT & 856 & WCSTL/WKHND & 796 \\
\hline GRISS/GUOST & 1,107 & WHEAL/WIRLD & 1,274 & GHCST/GRLSS & 855 & WHTKL/WTRLD & 829 \\
\hline
\end{tabular}

\section{APPENDIX B-4}

Mean Correct Latencies (in Milliseconds) for Different Pseudowords in Experiment 2

\begin{tabular}{lrr} 
& \multicolumn{2}{c}{ Type of Comparison } \\
\cline { 3 - 4 } & Whole & First-Letter \\
\hline First Letter Pairs & & 1,153 \\
BOACH/TOACH & 1,124 & 935 \\
BLIME/FLIME & 1,172 & 878 \\
BLOAD/FLOAD & 893 & 1,258 \\
BAUND/RAUND & 977 & 978 \\
BREIN/GREIN & 1,196 & 1,145 \\
BRIVE/GRIVE & 931 & 1,167 \\
CLESS/GLESS & 1,354 & 906 \\
CAUNT/MAUNT & 1,019 & 924 \\
DRISS/PRISS & 889 & 1,030
\end{tabular}


Appendix B-4 (Continued)

\begin{tabular}{lrlllrlr}
\hline \multicolumn{1}{c}{ Letter Difference } & \multicolumn{5}{c}{ Letter Difference } \\
\hline \multicolumn{1}{c}{ Third } & \multicolumn{3}{c}{ Fifth } & \multicolumn{3}{c}{ Third } \\
BLICK/BLECK & 1,182 & CHOUN/CHOUR & 1,299 & BLICK/CLECK & 1,055 & BLIST/GLISS & 919 \\
BREID/BROUD & 915 & CHOOK/CHOOR & 1,106 & BRUCK/TROCK & 862 & BLEID/FLEIT & 1,089 \\
FLISH/FLOSH & 1,021 & CLOIN/CLOIR & 1,221 & BROUD/TREUD & 755 & BRIND/GRINT & 953 \\
HARSE/HAUSE & 1,034 & CRAWD/CRAWN & 1,118 & CHACK/SHECK & 954 & BREWN/CREWD & 1,103 \\
MANTH/MAUTH & 923 & GREND/GRENT & 980 & CHOLL/SHULL & 864 & CHURT/SHURE & 1,231 \\
SHOLL/SHULL & 1,215 & GROON/GROOT & 1,122 & CHANK/THONK & 1,119 & CHOAK/SHOAT & 1,011 \\
SMILL/SMOLL & 1,368 & SHURE/SHURP & 1,517 & CLISH/FLOSH & 940 & CHOUR/SHOUN & 923 \\
STECK/STYCH & 935 & SHOAP/SHOAT & 1,137 & CRIFT/DROFT & 1,058 & CLOAR/FLOAS & 1,092 \\
THONK/THENK & 1,688 & SHEAK/SHEAT & 904 & HARSE/MAUSE & 1,012 & GLUND/SLUNT & 1,052 \\
TROCK/TRECK & 1,023 & STIRE/STIRM & 975 & MANTH/NARTH & 1,119 & GROAT/PROAN & 961 \\
\hline
\end{tabular}

\section{APPENDIX B-5}

Mean Correct Latencies (in Milliseconds) for Different Consonant Strings in Experiment 2

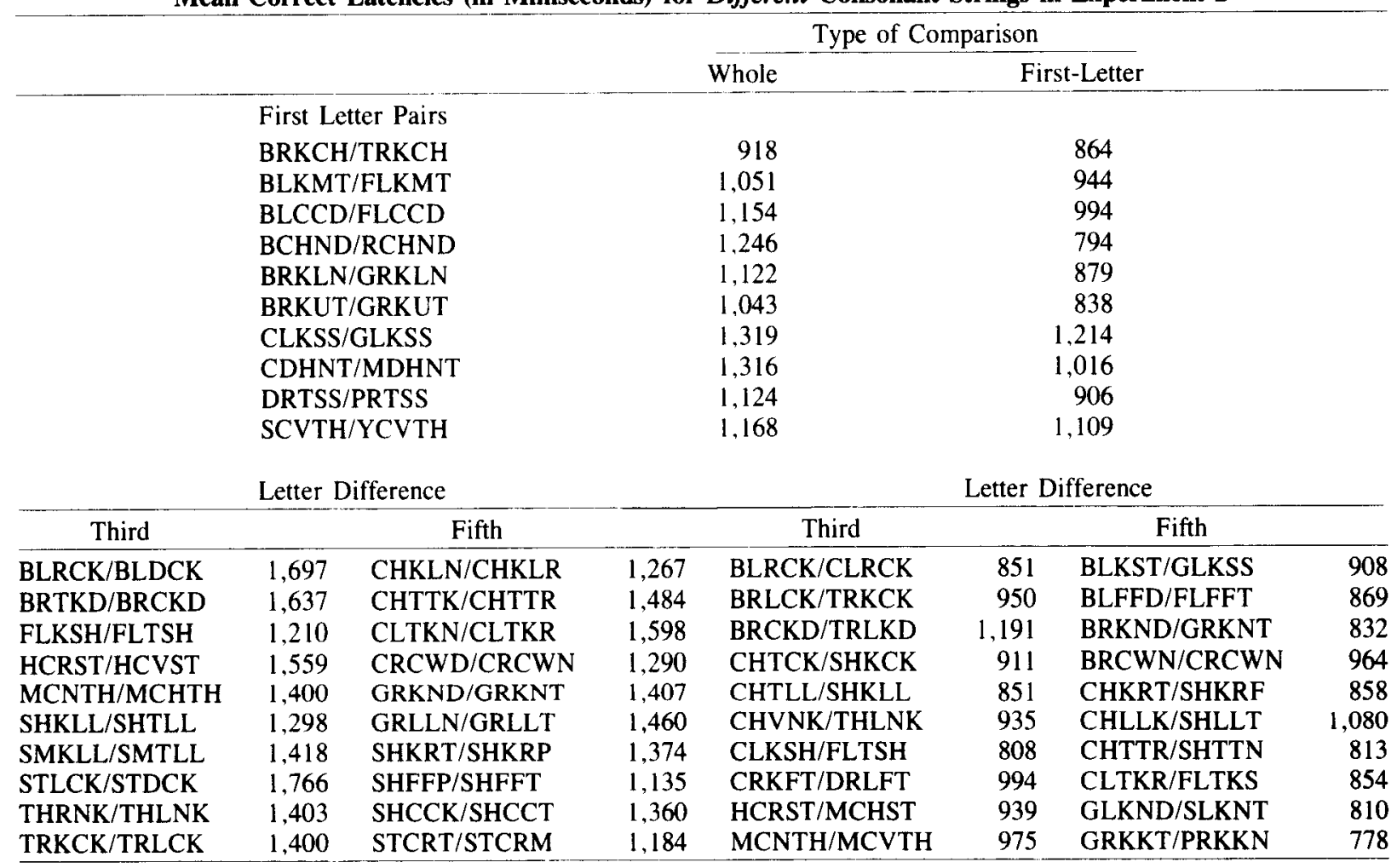

(Manuscript received January 25, 1985;

revision accepted for publication August 9,1985 .) 